\title{
Estudo etnobotânico e etnofarmacológico de plantas medicinais utilizadas na região de Matinhos - PR
}

\author{
Ethnobotanical and ethnopharmacological study of medicinal plants used in the \\ Matinhos region - Paraná
}

\author{
Luiz Everson da Silva*1, Diomar Augusto de Quadros² e Alzino José Maria Neto ${ }^{3}$ \\ ${ }^{1}$ Doutor, Setor Litoral, Universidade Federal do Paraná, Matinhos,Brasil \\ ${ }^{2}$ Mestre, Setor Litoral, Universidade Federal do Paraná, Matinhos, Brasil \\ ${ }^{3}$ Licenciado em Ciências, Setor Litoral, Universidade Federal do Paraná, Matinhos, Brasil
}

\begin{abstract}
Resumo
Neste trabalho, realizou-se uma investigação etnobotânica na região de Matinhos, no Litoral do Paraná, acerca do conhecimento e da percepção dos recursos vegetais existentes, buscando compreender quais as relações estabelecidas entre os moradores e o fragmento florestal, de forma a sistematizar o conhecimento popular de espécies medicinais e sua relação com o uso terapêutico. As informações foram coletadas entre agosto de 2011 e fevereiro de 2013. Dez informantes foram entrevistados sobre seus conhecimentos das espécies medicinais residentes nas comunidades rurais e nos bairros do município. A pesquisa revelou o uso de 80 espécies medicinais pertencentes a 48 famílias, dentre as quais Lamiaceae foi a mais citada. A principal parte utilizada na preparação dos chás é a folha e a preparação mais comum é a infusão. As espécies com maior número de citações são Chenopodium ambrosioides $L$. (mastruz) e Lippia alba (Mill) N.E. Br. (erva-cidreira), também associadas ao maior número de usos terapêuticos. Complementarmente, foram feitas extrações de óleo essencial por hidrodestilação.
\end{abstract}

Palavras-chave: Etnoconhecimento. Plantas medicinais. Indicação terapêutica

\begin{abstract}
This work was carried out is ethnobotanical research in the Matinhos region - in the Parana State coast, about knowledge and perception of existing plant resources, seeking to understand what the relations between the locals and the forest fragment, in order to systematize the popular knowledge of species medicinal and its relation to therapeutic use. The data were collected between August 2011 and February 2013. Ten informants were interviewed about their knowledge of medicinal species residing in rural communities and neighborhoods of the city. The survey revealed the use of 80 medicinal plant species belonging to 48 families that Lamiaceae was the most mentioned. The main part used in preparing of the teas is the leaf, and is the most common preparation is the infusion. In addition, we have carried out the essential oil extraction by hydrodestillation.
\end{abstract}

Keywords: Ethnoknowledge. Medicinal plants. Therapeutic indication 


\section{Introdução}

$\mathrm{O}$ uso de produtos naturais com propriedades terapêuticas pela civilização humana é antigo e, por um longo tempo, o uso de produtos minerais, vegetais e animais foi a principal fonte de substâncias de uso terapêutico (RATES, 2001).

Estima-se que $80 \%$ da população mundial utilizam, preferencialmente, a medicina tradicional nos cuidados primários da saúde, sendo que a maior parte das terapias tradicionais envolve o uso de plantas in natura ou produtos manufaturados a partir de seus extratos ou princípios ativos (WHS, 2006). Estima-se a existência de, aproximadamente, 250.000 espécies de plantas no mundo e, provavelmente, apenas $10 \%$ foram testadas em ensaios biológicos (HARVEY, 2000). Em alguns países de clima tropical, como o Brasil, a abundância de plantas medicinais oferece acesso a diversos produtos utilizados, através da automedicação, na prevenção e no tratamento de doenças, bem como no combate de pragas (MATOS et al ., 2001).

Nos últimos anos, têm crescido o interesse em terapias alternativas e no uso de produtos naturais, especialmente os derivados de plantas. Esse interesse deve-se a vários fatores, como a insatisfação com a medicina convencional (p.ex. efeitos adversos, terapia inefetiva), o uso incorreto e/ou abusivo de drogas sintéticas que resultam em efeitos colaterais e outros problemas. No Brasil, quinto país do mundo em consumo de medicamentos, estima-se em 24000 as mortes anuais por intoxicação medicamentosa e a um largo percentual da população mundial que não tem acesso ao tratamento farmacológico convencional (MORAES et al., 2009).

A mata atlântica apresenta uma grande diversidade de plantas com ação biológica não identificada e que precisam ser estudadas e valorizadas quanto a sua preservação neste bioma. Essa atitude contribui para inovação tecnológica, pela introdução de novos produtos menos impactantes aos aspectos socioambientais. No entanto, as mesmas requerem ações estratégicas, competências tecnológicas e esforços coletivos.

Para tal, estudos e pesquisas precisam ser intensificados, a fim de fornecerem subsídios importantes sobre espécies vegetais que possam ser utilizadas com atividade medicinal e/ou inseticida e, consequentemente, reunir valor econômico maior ao ecossistema florestal, do qual a ciência se apropria como fonte de informações para obtenção de novos conhecimentos científicos.

Neste contexto, estudos etnofarmacológicos e etnobotânicos no Brasil constituem um grande desafio, já que a variada flora brasileira tem sido progressivamente destruída e a medicina popular, uma rica mistura de conhecimentos indígenas, europeus e africanos, baseados em plantas medicinais tropicais, torna-se cada vez mais modificada pela cultura moderna (AMOROSO, 2002).

Nesse cenário, o litoral e sua proximidade com a mata atlântica configura-se como um importante objeto de pesquisas sobre plantas com usos terapêuticos, considerando sua representatividade, sua grande diversidade e a crescente perda da sua vegetação original, em ritmo acelerado, por forte pressão antrópica. Devido à diversidade biológica contida nos diferentes domínios da floresta ombrófila, é interessante notar que cada área situada neste espaço possui comunidades humanas com uma forma própria de manejo desse complexo mosaico de fitofisionomias. Portanto, cada estudo local se torna relevante devido às particularidades do objeto da pesquisa, isto é, a variação da representatividade de cada espécie para determinada comunidade.

Uma abordagem baseada no conhecimento popular das comunidades locais sobre a utilização das espécies medicinais foi sugerida por Bisht e colaboradores. Para eles, as plantas medicinais mais conhecidas entre as pessoas são as mais ameaçadas pelo uso excessivo e pela maior demanda, consequentemente, são as prioritárias para conservação (BISHT et al., 2006).

Vieira e colaboradores (VIEIRA et al., 2002) sugeriram critérios para definir espécies medicinais e aromáticas prioritárias para a conservação com base em aspectos farmacológicos, biológicos, comerciais, de uso e de coleta (quadro 1). No entanto, para esse tipo de abordagem é necessário que as espécies, no geral, tenham estudos científicos básicos e informações detalhadas para inserção nos critérios estabelecidos.

Quadro 1 - Critérios utilizados para priorizar plantas medicinais e aromaticas para a conservação proposto por Vieira et al. (2002)

\begin{tabular}{|c|c|}
\hline Aspectos & Critérios \\
\hline farmacologia & 1- comprovada; 2- em estudo; 3- sem estudo. \\
\hline freqüência de ocorrência & 1- pouco freqüente; 2 - freqüente; 3 - abundante. \\
\hline mercado/demanda & $\begin{array}{l}\text { 1- externo; } 2 \text { - interno; } 3 \text { - regional; 4- sem valor } \\
\text { de mercado. }\end{array}$ \\
\hline parte usada & 1- raiz; 2- casca/caule; 3- flor/fruto/folha/óleo. \\
\hline pressão antrópica & 1- alta; 2- regular; 3- baixa. \\
\hline Princípio ativo & $\begin{array}{l}\text { 1- identificado; } 2 \text { - em estudo; } 3 \text { - sem estudo } \\
\text { químico. }\end{array}$ \\
\hline produção & $\begin{array}{l}\text { 1- extrativismo; 2- manejo sustentado; } 3 \text { - em } \\
\text { cultivo. }\end{array}$ \\
\hline Uso popular & $\begin{array}{l}\text { 1- amplo; 2- local; 3- sem uso popular } \\
\text { expressivo. }\end{array}$ \\
\hline
\end{tabular}

Apesar da grande diversidade de plantas medicinais nativas utilizadas no Brasil (muitas provenientes de populações silvestres) e do cenário atual de degradação das formações vegetacionais brasileiras, estudos estabelecendo espécies prioritárias para conservação são escassos. Estudos desse tipo, envolvendo aspectos biológicos, econômicos, culturais e sociais, tornam-se necessários tanto a nível nacional quanto regional e local.

Para isso, a valorização do etnoconhecimento em relação às propriedades terapêuticas das plantas e o conhecimento popular têm-se mostrado uma forte subsi- 
diária ao conhecimento técnico-científico. A acumulação de informações sobre o uso de recursos naturais por populações tradicionais tem oferecido, aos cientistas, modelos de uso sustentável desses mesmos recursos.

Por outro lado, óleos essenciais fazem parte dos princípios ativos dos vegetais. São metabolismos secundários que as plantas podem ou não desenvolver, dependendo das variáveis ecológicas, pois as plantas produzem estes compostos na medida em que precisam desenvolver estratégias de sobrevivência e adaptação. Apesar da existência de um controle genético, as mesmas espécies de plantas podem apresentar modificações diferentes, uma vez que as substâncias são resultantes da interação de processos bioquímicos, fisiológicos, ecológicos e evolutivos.

Em geral, os princípios ativos são constituintes químicos com capacidade de produzir uma ação ou um efeito terapêutico ao organismo dos humanos e dos animais. São, ainda, divididos em grupos segundo suas características químicas e seus efeitos biológicos.

Dentre os princípios ativos, encontramos o grupo dos óleos essenciais, constituídos por substâncias orgânicas voláteis, obtidas de plantas aromáticas. Podem ser encontrados em flores, folhas, caules, raízes, sementes e em madeiras. Além disso, possuem grande aplicação na perfumaria, na cosmética, nos alimentos e nos medicamentos. Sua ação terapêutica está relacionada pelas suas ações anti-inflamatórias, antissépticas, antiespasmódica e por ser um anestésico local.

O método de extração varia de acordo com a parte a ser extraída e a substância a ser obtida. Dentre os métodos, a destilação por arraste a vapor é o mais empregado; se mostra bastante eficaz a um baixo custo, sendo ainda o mais adequado para a extração de determinadas substâncias de uma planta.

Este trabalho teve como objetivo realizar um levantamento de plantas medicinais no Município de Matinhos - PR, fazendo um resgate das práticas terapêuticas, pesquisando as partes da planta utilizadas, as formas de preparo, a dosagem, as vias de administração e as indicações de uso.

\section{Materiais e métodos}

A área de estudo, Matinhos - PR, situa-se a $25^{\circ} 49^{\prime} 04^{\prime \prime}$ de latitude e $48^{\circ} 32^{\prime} 34^{\prime \prime}$ de longitude. Antiga terra habitada pelos Carijós, é um município do litoral paranaense, situada a $111 \mathrm{~km}$ de Curitiba. Privilegiado por uma geografia diversificada, a qual compreende parte do maciço montanhoso da Serra da Prata e as amplas áreas da planície costeira da Praia de Leste. Os dados foram coletados entre agosto de 2011 e fevereiro de 2013. Dez informantes, de ambos os sexos, de idade variando de 41 a 84 anos, escolhidos por consulta prévia, foram entrevistados sobre seus conhecimentos das espécies me- dicinais residentes nas comunidades rurais e nos bairros do município. Faziam parte do questionário questões como nome, residência, idade, sexo, grau de instrução, ano de residência no lugar, região de origem e como e quais plantas medicinais são conhecidas, as formas de uso e o modo de preparação para as principais enfermidades e/ou sintomas. Cada entrevista foi registrada a fim de preservar o registro das informações. Entre os 10 entrevistados do município de Matinhos - PR, sete residem na área urbana e três na área rural do município (Figura 1). A pesquisa foi submetida ao Comitê de Ética da Universidade Federal do Paraná, constando a aprovação sobre o CAAE (Certificado de Apresentação para Apreciação Ética): número 771.360.

As plantas descritas foram fotografadas e sua identificação foi confirmada por comparação com espécie autêntica armazenada no herbário da UFPR. As diversas informações obtidas foram classificadas em categoria de análise, para melhor estudar a frequência de respostas semelhantes.

Primeira etapa: os conhecedores da utilização de plantas medicinais foram identificados e cadastrados pessoalmente, por meio do preenchimento de uma ficha contendo os seguintes dados: endereço, idade, sexo, estado civil e profissão, tempo de residência no lugar.

Segunda etapa: os sujeitos cadastrados foram contatados para verificar sua disponibilidade e seu interesse em transmitir as informações sobre utilização de plantas para fins medicinais, assinando um termo de consentimento.

Terceira etapa: a cada sujeito foi aplicado um questionário semiestruturado, baseado em Rodrigues e Carvalho, a fim de identificar quais espécies de plantas são conhecidas, sua forma de utilização (preparo, dosagem e administração) e a finalidade do uso (RODRIGUES; CARVALHO, 2001). As entrevistas foram gravadas, com o consentimento dos sujeitos, para facilitar a transcrição dos dados.

Quarta etapa: no mês de dezembro, foi feita a coleta das plantas citadas, com o auxílio de cada sujeito, em locais variados, incluindo ambientes urbanos (quintal, praça, jardim) e nativos (campo, mata).

\subsection{Coleta do material vegetal}

O material vegetal foi coletado na região litorânea do Paraná durante o período vegetativo e reprodutivo das espécies. Quando requerido, as folhas foram secas à temperatura ambiente e à sombra até massa constante.

\subsection{Obtenção dos óleos essenciais}

O material vegetal foi previamente limpo, armazenado em sacos plásticos sob refrigeração e submetido à hidrodestilação, num período máximo de 48 h após a coleta. O óleo essencial foi obtido por hidrodestilação, durante um tempo máximo de 4 horas, em aparelho 
Clevenger modificado (GOTTLIEB; MAGALHÃES, 1960). Após a extração, os óleos essenciais foram coletados e a remoção do excesso de água foi feita, empregando uma pipeta Pasteur. Em seguida, os óleos foram secos com sulfato de magnésio anidro. Quando o volume de óleo extraído foi inferior a $1 \mathrm{~mL}$, diclorometano bidestilado foi empregado no seu isolamento. A massa do óleo extraído será determinada em balança analítica, para cálculo do rendimento, utilizando as seguintes expressões: rendimento seco $(\%)=($ massa do óleo $/$ massa do material vegetal seco) $\times 100$; e rendimento fresco $(\%)=$ (massa do óleo/massa do material vegetal fresco) x 100 . Finalmente, foi armazenado em refrigerador a $4^{\circ} \mathrm{C}$ sob atmosfera inerte.

\section{Resultados e discussão}

Os entrevistados indicaram diferentes espécies de plantas, taxonomicamente identificadas com 80 espécies distintas, distribuídas em 48 famílias, sendo a família Lamiaceae com o maior número de espécies. As plantas mais citadas foram hortelã, boldo, melissa e alecrim. A parte vegetal mais utilizada na preparação das soluções é a folha, com $57,64 \%$, seguida de flores e da casca, com 9,4\%. A forma mais comum de preparação é a infusão. Todos os entrevistados demonstram conhecimento sobre as plantas medicinais e relatam que este provém de gerações passadas. De acordo com estudos prévios (ALBUQUERQUE, 2013; AMOROSO, 1996), a principal

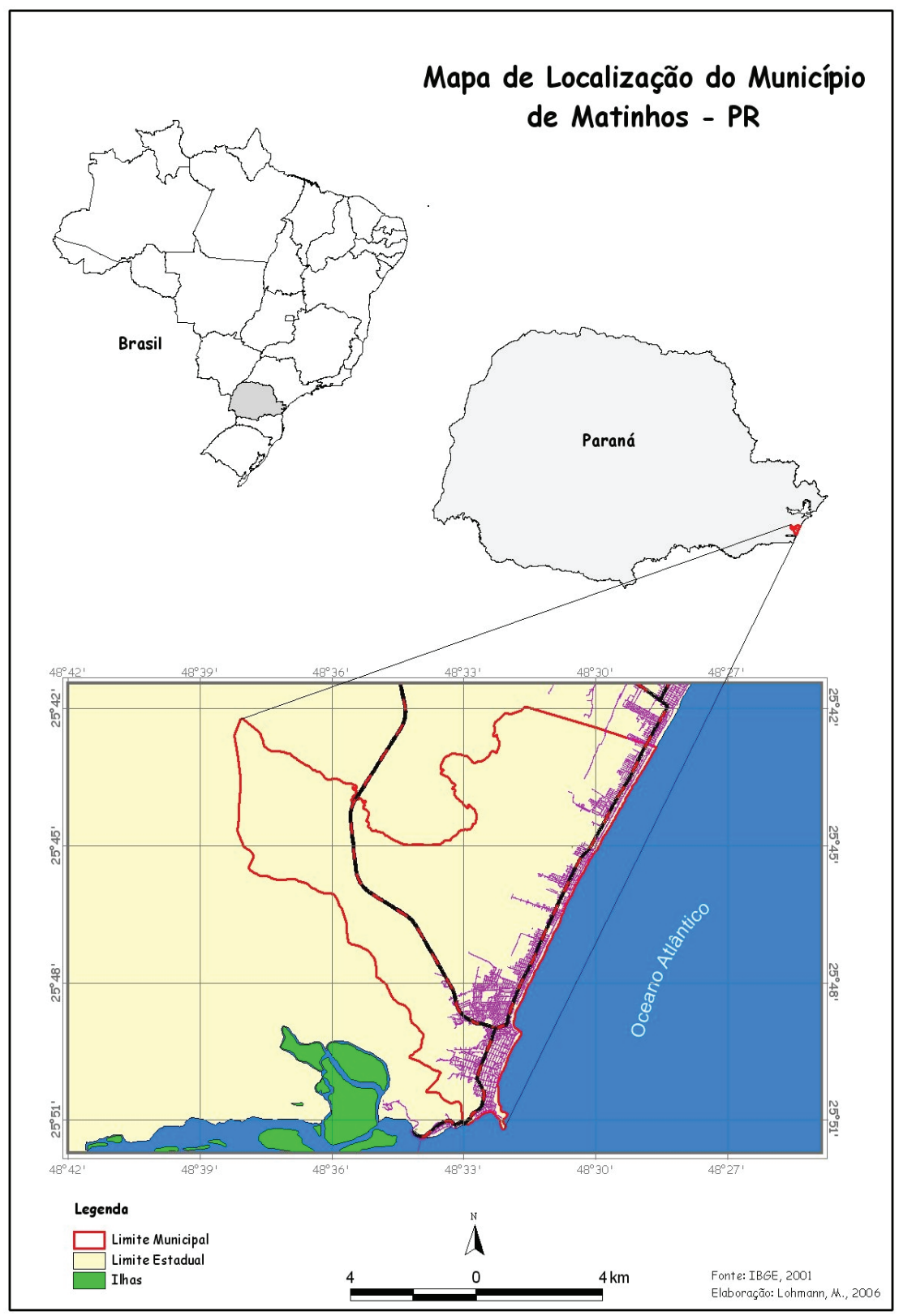

Figura 1 - Mapa do Paraná e a região de Matinhos 
forma de transmissão de conhecimento nas sociedades tradicionais é a verbal, e a transmissão entre gerações requer contato intenso entre os membros mais jovens e mais velhos da comunidade. Neste estudo, 03 dos entrevistados, eram homens e 07 mulheres. Existem diferenças entre o conhecimento do homem e da mulher. Em geral, as mulheres dominam o conhecimento das plantas que crescem perto da residência, enquanto os homens sabem mais as plantas que crescem sobre os campos. Esta especialização não é rígida, algumas mulheres conhecem os recursos dos campos, bem como seus maridos. Mulheres e homens, tradicionalmente, têm funções distintas, e cada um dos sexos se move através destes espaços de maneira diferente.

As enfermidades mais comuns na qual as plantas são utilizadas relacionam-se com processos respiratórios, inflamações e cicratizações, ansiedade e dores estomacais. Isto pode ser relacionado com a posição geográfica do município, que apresenta um clima sub-tropical com temperatura média anual de $19,5^{\circ} \mathrm{C}$ e chuvas constantes durante todo o ano (SECRETARIA DE ESTADO DA SAÚDE DO PARANÁ, 2013). Os processos inflamatórios relacionam-se, também, com dores de garganta, e o uso nas cicatrizações estão associadas com cortes oriundos de atividades pesqueiras que, tradicionalmente, identificam a região.

Algumas plantas identificadas como medicinais eram cultivadas na horta ou no quintal da casa dos entrevistados, outras eram obtidas no campo, não sendo observado predomínio de um local de coleta. Silva e colaboradores comentam que, ao trazerem mudas do campo para seus quintais, os manipuladores de plantas colaboram para a propagação de espécies de seu interesse, inclusive em habitats diferentes, modificando o meio natural (SILVA et al., 2006).

A maior parte dos entrevistados começou a observar e fazer uso de plantas medicinais com até vinte anos de idade, tendo aprendido ainda na infância, geralmente observando os pais. Tal relação foi notada, também, por MING e AMARAL JÚNIOR (2003), os quais referiram que este fato confirma a tradição de transmissão de conhecimentos entre gerações.

Foi relatado, algumas vezes, uso de medicamento convencional associado ao uso de plantas, denotando a influência da medicina ocidental na cultura popular, o que também pode ser observado na atribuição de nomes farmacêuticos às plantas utilizadas ou cultivadas. Porém, convém ressaltar que a associação de mais de uma espécie vegetal, constituindo as misturas, é comum na terapêutica de culturas diversas. Entretanto, sabe-se que as misturas devem se restringir a um número reduzido de espécies, uma vez que podem trazer efeitos inesperados, em virtude das interações de seus constituintes químicos. Nesse sentido, Arnous e colaboradores destacam que a associação de ervas medicinais deve ser administrada com critério e sob orientação médica, pois apresentam, muitas vezes, efeitos farmacológicos similares, podendo potencializar suas ações (ARNOUS et al.,2005). Visualiza-se aqui a necessidade de atividade de extensão multidisciplinar junto aos manipuladores e usuários de plantas, visando esclarecer a utilização segura de plantas para fins terapêuticos.

Entre as preparações terapêuticas mais utilizadas, existe uma similaridade com os dados de Coelho-Ferreira (2000), confirmando os modos de preparo parecidos. Neste trabalho as preparações são apresentadas como indicadas pela comunidade:

Chás: podem ser preparados de diversos modos, dependendo da parte da planta a ser utilizada. A infusão é recomendada quando se utiliza as partes mais tenras das plantas, como folhas, flores, inflorescências e frutos, devendo ser preparada vertendo água sobre o material e deixando em repouso por cerca de 20 minutos, depois coar e ingerir. A vasilha recomendada para fazer o preparo deve ser de louça ou de vidro, "para não se perder as forças dos vegetais". A decocção é usada para as partes das plantas mais duras, como cascas, raízes, sementes, caules e rizomas, preparado juntando o material em uma vasilha com água fria e levada ao fogo até a fervura. Após, coar e administrar as dosagens recomendadas.

Os chás são as preparações terapêuticas mais populares e são usados para quase todas as indicações de cura e prevenção das doenças, como, por exemplo, tosse; gripe; sífilis; diarreia; problemas de fígado, intestino ou coração; também servem para regular a menstruação; como calmante; como diurético; para vermes; para cólicas e dores em geral; para pressão alta, colesterol, insônia, gonorréia, ressaca, derrame, taquicardia, rubéola, prisão de ventre; servindo, também, como analgésico.

Lavagem: é preparada como chá (por decocção ou infusão) e usada para fazer limpezas de ferimentos, lavagens vaginais, reumatismo, corrimento, lavar olhos inflamados, impinges, frieiras, sarna, erisipelas, asseio vaginal, limpeza de queimaduras, entre outros. Os chás para lavagens são usados externamente.

Banhos: são, também, usados como os chás, que podem ser frios ou mornos e, em geral, banha-se a cabeça e, em algumas vezes, o corpo todo. É muito usado em: gripes, resfriados, caspa, bronquite, laringite, lêndeas, piolhos, asma, sarampo, catapora, sinusite, reumatismo, queda de cabelos, calmante, relaxamento, alergias e em problemas de ordem místicas, feitiços, mal-olhados, criança aborrecida, quebranto, moleza de corpo, limpeza de corpo, ganhar felicidade, abrir os caminhos da vida e outros.

Emplastos: são preparados fazendo uma pasta do material com água, cachaça ou azeites, que pode ser quente ou fria, que se coloca em uma gaze ou pano, aplica-se na parte afetada e faz-se um envoltório para manter por determinado tempo o preparado. É indicado para reumatismo, abscessos, baques, inchaços, problemas de pele, coceiras, frieiras, cicatrizar ferimentos, picadas de insetos e queimaduras (Tabela 1). 
Tabela 1 - Plantas medicinais utilizadas na região de Matinhos

\begin{tabular}{|c|c|c|c|}
\hline & Nome popular & Nome científico / Família & Uso Medicinal \\
\hline 1 & Alfavaca & Ocimum-basilicum / Labiateae & $\begin{array}{l}\text { infecção de bexiga, digestivo, } \\
\text { cicatrizante; }\end{array}$ \\
\hline 2 & Alfazema & Lavandula SP / Lamiaceae & $\begin{array}{l}\text { calmante, dores de cabeça, alivia } \\
\text { sangramento (gengivite); }\end{array}$ \\
\hline 3 & Alecrim & Rosmarius officinallis / Labiateae & $\begin{array}{l}\text { digestivo, abre o apetite, dores } \\
\text { no peito e contra a tosse; }\end{array}$ \\
\hline 4 & Amora & Morus nigra L. / Moraceae & contra dor de garganta; \\
\hline 5 & $\begin{array}{l}\text { Amoreira } \\
\text { branca }\end{array}$ & Morus Alba L. / Moraceae & $\begin{array}{l}\text { anti-hipertensivo, infecções de } \\
\text { garganta; anti-hipertensivo }\end{array}$ \\
\hline 6 & Anis & Pimpenella anisum / Apiaceae & $\begin{array}{l}\text { calmante (sistema nervoso), } \\
\text { contra cólicas; }\end{array}$ \\
\hline 7 & Araçá & Psidium araçá / Myrtaceae & dor de barriga; \\
\hline 8 & Aroeira & $\begin{array}{l}\text { Schinus therebin sativum / } \\
\text { Anacardiaceae }\end{array}$ & cicatrizante; \\
\hline 9 & Arruda & Ruta graveolens / Asteraceae & contra dores e tosse; \\
\hline 10 & Azedinha & Rumex acetosol / Oxalidáceas & $\begin{array}{l}\text { contra aftas, sapinho, depurador } \\
\text { de sangue (limpeza); }\end{array}$ \\
\hline 11 & Babosa & Aloe arborescens / Aloaceae & $\begin{array}{l}\text { queimaduras, fortalece o couro } \\
\text { cabeludo; }\end{array}$ \\
\hline 12 & Bacupari & Rhedia gardneriana planch / Clusiaceae & cicatrizante; \\
\hline 13 & Bananeira & $\begin{array}{l}\text { Musa paradisiaca, musa sapientium, } \\
\text { musa cavendishii / Musaceae }\end{array}$ & bronquite; \\
\hline 14 & Batata doce & Convolvulus batatas / Convolvulaceae & inflamação no dente (gargarejo); \\
\hline 15 & Beldroega & Portulaca oleracea / Portulacáceas & combate vermes e é diurética; \\
\hline 16 & Boldo & Peumus boldo / Minimiáceae & $\begin{array}{l}\text { bom para o fígado, estômago, } \\
\text { hepatites, prisão de ventre; }\end{array}$ \\
\hline 17 & Cana de açúcar & Sacchrum ifficinarum / Poaceae & $\begin{array}{l}\text { gripe, contra anemia, fraqueza } \\
\text { do coração e mantém a força } \\
\text { muscular; }\end{array}$ \\
\hline 18 & Cana do brejo & Costus spirallis/Zingiberaceae & contra inflamação na bexiga; \\
\hline 19 & Camomila & $\begin{array}{l}\text { Matricharia chamomilla,syn.chamomilla } \\
\text { recutita/Asteraceae }\end{array}$ & calmante; \\
\hline 20 & Capim limão & Cymbopogon citratus/Poaceae & $\begin{array}{l}\text { calmante, digestivo e contra a } \\
\text { Azia; }\end{array}$ \\
\hline 21 & $\begin{array}{l}\text { Catinga de } \\
\text { mulata }\end{array}$ & $\begin{array}{l}\text { Tanacetum vulgare / Tanacetum } \\
\text { vulgare }\end{array}$ & $\begin{array}{l}\text { dores musculares, febre, } \\
\text { reumatismo; }\end{array}$ \\
\hline 23 & Caúna & Llex paraguasins / Aquifoliaceae & estimulante, diurética; \\
\hline 24 & Cavalinha & Equisetum arvense / Equisetaceae & $\begin{array}{l}\text { contra dores de coluna e } \\
\text { próstata; }\end{array}$ \\
\hline 25 & $\begin{array}{l}\text { Chapéu de } \\
\text { couro }\end{array}$ & $\begin{array}{l}\text { Echinodorus macrophyllus / } \\
\text { Alismataceae }\end{array}$ & diurético; \\
\hline 26 & Chuchu & Sechium edule / Cucurbitáceae & anti-hipertensivo \\
\hline 27 & Chifre de veado & $\begin{array}{l}\text { Platycerium } \\
\text { bifurcatum/Polypodiaceae }\end{array}$ & contra dor de barriga; \\
\hline 28 & Couve & Brassica / Brassicaseae & calmante estomacal; \\
\hline
\end{tabular}


Tabela 1 - Plantas medicinais utilizadas na região de Matinhos, Continuação...

\begin{tabular}{|c|c|c|c|}
\hline & Nome popular & Nome científico / Família & Uso Medicinal \\
\hline 29 & Cupiúva & Copaifera langsdorffii / Caesalpinaceae & anti-inflamatória, cicatrizante; \\
\hline 30 & Embaúba & Cecropia hololenca / Cecropiaceae & asma, tosse, coqueluche; \\
\hline 31 & $\begin{array}{l}\text { Erva de santa } \\
\text { maria }\end{array}$ & $\begin{array}{l}\text { Chenopodium ambrosioides / } \\
\text { Chenopodiáceas }\end{array}$ & $\begin{array}{l}\text { anti-inflamatória, aumenta a } \\
\text { respiração; }\end{array}$ \\
\hline 32 & Erva baleeira & Cordia curassavica / Boraginaceae & contra dores musculares; \\
\hline 33 & Erva doce & Pimpenelha anisum / Apiaceae & $\begin{array}{l}\text { dor de barriga, cólicas, } \\
\text { problema de gases, diurético; }\end{array}$ \\
\hline 34 & Erva- mate & Llex paraguasins / Aquifoliaceae & estimulante mental e diurético; \\
\hline 35 & $\begin{array}{l}\text { Espada de são } \\
\text { Jorge }\end{array}$ & Sansevieira trifasciata / Ruscáceas & cicatrizante; \\
\hline 36 & Gengibre & Zingiber officinale / Zingiberaceae & $\begin{array}{l}\text { dor de cabeça, resfriado, } \\
\text { problemas respiratórios, } \\
\text { Roquidão; }\end{array}$ \\
\hline 37 & Girassol & $\begin{array}{l}\text { Helianthus anuus populfimirassol / } \\
\text { Asteraceae }\end{array}$ & febrão, colesterol; \\
\hline 38 & Goiaba & Psidium guajava / Myrtaceae & dor de barriga; \\
\hline 39 & Graviola & Anona muricata L / Annonaceae & câncer; \\
\hline 40 & Guaco & $\begin{array}{l}\text { Mikania glomerata, m.laevigata / } \\
\text { Asteraceae }\end{array}$ & gripe, resfriado; \\
\hline 41 & Guanandi & Colophyllum brasiliensis / Clusiaceae & contra diabetes; \\
\hline 42 & Guiné & $\begin{array}{l}\text { Petiveria tetranda Gomez, } \\
\text { Petiveria alliacea / Phytollacaceae }\end{array}$ & $\begin{array}{l}\text { enxaqueca, falta de memória, } \\
\text { reumatismo, paralisia, estados } \\
\text { nervosos; }\end{array}$ \\
\hline 43 & Hortelã & Mentha SP. / Lamiaceae & $\begin{array}{l}\text { contra vermes, inflamação de } \\
\text { garganta; }\end{array}$ \\
\hline 44 & $\begin{array}{l}\text { Hortelã } \\
\text { pimenta }\end{array}$ & Mentha piperita / Lamiaceae & lombriga; \\
\hline 45 & Ingá & Ingá sessilis / Mimosaceae & laxativa; \\
\hline 46 & Inhame taioba & Colocasia esculenta / Aráceas & $\begin{array}{l}\text { distringente, anti-diabético, } \\
\text { anti reumático; }\end{array}$ \\
\hline 47 & Ipê amarelo & Tabebuia Alba / Bignoniaceae & anti-reumático; \\
\hline 48 & $\begin{array}{l}\text { Jacarandá- } \\
\text { lombriga }\end{array}$ & Andira anthelminthica / Fabaceae & contra vermes e lombriga; \\
\hline 49 & Laranja & Citrus / Rutaceae & calmante, gripe; \\
\hline 50 & Limoeiro & Citrus limonum / Rutáceas & dores de garganta, gripe; \\
\hline 51 & Lírio & Lilium SP / Liliaceae & bom para a vista; \\
\hline 52 & Losna & Artmisia absinthium / Asteraceae & $\begin{array}{l}\text { cicatrizante, calmante, } \\
\text { dor de cabeça; }\end{array}$ \\
\hline 53 & Manjericão & Ocumum basulicum / Lamiaceae & $\begin{array}{l}\text { infecção na pele, roquidão, } \\
\text { bronquite, insônia, rachadura } \\
\text { nos mamilos; }\end{array}$ \\
\hline 54 & Manjerona & Origanum majorona / Labiatae & cólica e calmante; \\
\hline 55 & Mamão & Carica papaya / Caricaceae & contra bronquite; \\
\hline 56 & Maracujá & $\begin{array}{l}\text { Passiflora alata, p.edulis, p.incarnatal } \\
\text { Passifloraceae }\end{array}$ & calmante e cicatrizante; \\
\hline
\end{tabular}


Tabela 1 - Plantas medicinais utilizadas na região de Matinhos, Continuação...

\begin{tabular}{|c|c|c|c|}
\hline & Nome popular & Nome científico / Família & Uso Medicinal \\
\hline 57 & Maricá & $\begin{array}{l}\text { Leguminosae mimosoideae / } \\
\text { Mimosaceae }\end{array}$ & $\begin{array}{l}\text { combate asma, bronquite e } \\
\text { febre; }\end{array}$ \\
\hline 56 & Marcela & Achyrocline satureoides / Asteraceae & dor de bexiga, anti-inflamatório; \\
\hline 58 & Melissa & Melissa officinalis / Labiatae & insônia; \\
\hline 59 & Menta-pimenta & Menta piperita / Lamiaceae & contra febre, tosse e gripe; \\
\hline 60 & Mil folhas & Achillea millefolium / Asteraceae & $\begin{array}{l}\text { cicatrizante, calmante, } \\
\text { dor de cabeça; }\end{array}$ \\
\hline 61 & Milome & $\begin{array}{l}\text { Aristolochia cymbifera martius / } \\
\text { Dilcniáceas }\end{array}$ & dor de barriga; \\
\hline 62 & Morango & Fragaria vesca / Rosaceae & $\begin{array}{l}\text { contra inflamações de rins e } \\
\text { bexiga, retenção de urina; }\end{array}$ \\
\hline 63 & Novalgina & Achillea millefolium L / Asteraceae & gripe e tosse; \\
\hline 64 & Orégano & Origanum vulgare / Lamiaceae & contra tosses, febre e é digestiva; \\
\hline 65 & Paudalho & Gallesia gorarema / Phytolaccaceae & adstringente; \\
\hline 66 & Pata de vaca & Bauhinia forticata / Leguminoseae & $\begin{array}{l}\text { diabete, diurética, prisão de } \\
\text { ventre; }\end{array}$ \\
\hline 67 & Pé de galinha & Eleusine / Poaceae & dor de garganta; \\
\hline 68 & Penicelina & $\begin{array}{l}\text { Alternanthera dentata (moench) / } \\
\text { Amaranthaceae }\end{array}$ & inflamação de garganta; \\
\hline 69 & Pessegueiro & Prunus brasiliensis / Rosaceae & para tosses e asmas; \\
\hline 70 & $\begin{array}{l}\text { Picão ou Pico- } \\
\text { Pico }\end{array}$ & Bidens sulphurea / Asteraceae & $\begin{array}{l}\text { inflamação de rim, contra } \\
\text { reumatismo, infecção de bexiga } \\
\text { e pedras na vesícula; }\end{array}$ \\
\hline 71 & Pitanga & Eugenia unifloa L. / Myrtaceae & diarreia; \\
\hline 72 & Poejo & Mentha polegium / Labiatae & $\begin{array}{l}\text { calmante, digestivo, favorece o } \\
\text { sono, alivia cólicas; }\end{array}$ \\
\hline 73 & Quebra-pedra & Philanthus niruri / Euphorbiaceae & $\begin{array}{l}\text { pedras no rim, diurética, } \\
\text { infecção de bexiga e renais; }\end{array}$ \\
\hline 74 & Rosa-branca & Rosa albal L. / Rosaceae & $\begin{array}{l}\text { digestiva, combate alergias e } \\
\text { conjuntivite; }\end{array}$ \\
\hline 75 & Sabugueiro & Sambucus SP / Caprifoliaceae & sarampo; \\
\hline 76 & Salsinha & Petreselinum sativum / Apiaceae & $\begin{array}{l}\text { diurética, estimulante, digestiva, } \\
\text { auxilia na menstruação; }\end{array}$ \\
\hline 77 & Samambaia & $\begin{array}{l}\text { Nephrolepis polypodium / } \\
\text { Euphorbiaceae }\end{array}$ & combate furúnculos; \\
\hline 78 & Tanchagem & $\begin{array}{l}\text { Pantago australis, p.major; p.lanceolata / } \\
\text { Plantaginaceae }\end{array}$ & inflamação na bexiga; \\
\hline 79 & $\begin{array}{l}\text { Tomate do } \\
\text { campo }\end{array}$ & Salanum lycopersicum / Solanáceas & $\begin{array}{l}\text { banho para doenças de pele, } \\
\text { gripes, tosses e reumatismo; }\end{array}$ \\
\hline 80 & Tomilho & Thymus vulgaris / Labiatae & digestivo. \\
\hline
\end{tabular}

Neste estudo também foi possível identificar semelhanças no uso de plantas medicinais de locais próximos ao litoral, e que sofre influência ou influencia as relações aqui estabelecidas historicamente. A pesquisa relatada por Gomes e colaboradores (2001), realizada em Morretes, cidade distante $50 \mathrm{Km}$ de Matinhos, identificou espécies descritas em nosso estudo como destaque no uso por aquela população. Dentre as plantas mais citadas destacou-se: FÍGATIL (Chelidonium majus - Papaveraceae) - 27,42\%; ALECRIM (Rosmarius officinalis - Labiatae) 23,32\%; LOSNA (Artemisia absinthium L - Asteraceae) 22,20\%; ARRUDA (Ruta graveolens L - Rutaceae) - 18,90\%; 
SÁLVIA (Salvia officinali - Labiatae) - 17,35 \%; CATINGA DE MULATA (Tanacetum vulgare L - Asteraceae) - 12,87\%; ERVA DE SANTA MARIA (Chenopodium ambrosioides L. - Chenopodiaceae) - 8,95\%; CONFREI (Symphytum officinale L. - Boraginaceae) - 8,02\%; BARDANA (Actium minus - Asteraceae) - 5,59\%; ERVA MOURA (Solanum nigrum L. - Solanaceae) - 5,41\%; AROEIRA (Schinus terebenthifolius Raddi - Anacardiaceae) - 5,22\%; ARTEMISIA (Artemisia vulgaris L - Asteraceae) - 4,85\%; SABUGUEIRO (Sambucus nigra - Caprifolliacea) - 3,54\%; GUINÉ (Petiveria alliacea - Phytolaccaea) - 3,35\%; ARNICA (Arnica montana - Asteraceae) - 2,98\% e BABOSA (Aloe vera L Asphodelaceae) - 2,79\%. Tais plantas são utilizadas pela população como medicinais e consideradas, na maioria das vezes, benéficas e inócuas para saúde. Em nossa investigação, observamos que algumas destas espécies relacionam-se com processos inflamatórios associados ao sistema respiratório, o que também foi observado no estudo conduzido por Battisti e colaboradores (2013).

Com relação à importância do uso medicinal, podemos destacar o trabalho de Lunardelli (2006), ao abordar que o uso das plantas medicinais é amplamente aceito pelas comunidades e profissionais de saúde como opção terapêutica, em virtude do baixo custo, do reduzido efeito colateral e da sua eficácia já comprovada cientificamente. As patologias mais comuns na atenção primária à Saúde incluíam as doenças respiratórias, gênito-urinárias, dermatologias e músculo esqueléticas. No decorrer da pesquisa, foi constatado que tais patologias são tratadas com plantas medicinais pelas comunidades antes mesmo do atendimento pela Unidade de Saúde Local. O desenvolvimento da pesquisa permitiu reconhecer que a maior parte das plantas referidas pelas comunidades são nativas, como em nossa investigação, destacando-se: a erva baleeira (Cordia verbenacea), erva de santa maria (Chenopodium ambrosioides), catinga de mulata (Tanacetum vulgare), guaco (Mikania glomerata) e algumas exóticas, como Mentha spp, Rosmarinus officinalis L., gengibre (Zingiber officinale), tansagem (Pantago australis).

Outras espécies que merecem destaque em função do uso regional no litoral paranaense são: amoreira (Morus nigra e Morus alba) e cavalinha (Equisetum arvense) e a erva baleeira (Cordia verbenacea). Segundo a medicina popular, a amoreira apresenta funções medicinais, podendo os frutos serem utilizados como laxativos, vermífugos, expectorantes, eméticos e hipoglicêmicos. As raízes e as cascas podem ser utilizadas no tratamento de anemia, artrite, reumatismo, hipertensão e diabetes, além de terem ação expectorante e diurética (PIEKARSKI, 2013). Na medicina alternativa, a cavalinha é utilizada como cataplasma para o tratamento de feridas, ducha para leucorréia, colírio para conjuntivite, embebição para chulé, lavagem para fortalecer os cabelos e líquido para limpeza bucal no tratamento de gengivite. A erva baleeira tem ação anti-inflamatória comprovada e já está presente no primeiro medicamento genuinamente brasileiro (GILBERT; FAVORETO, 2012). Estas espécies fazem parte da lista do RENISUS (CARVALHO, 2011) com potencial para avançar com produtos de valor agregado da biodiversidade nacional.

Os estudos conduzidos com as espécies selecionadas para a extração do óleo mostraram-se promissores. A espécie Eriobotrya japonica, em estudos prévios, tem apresentado efeitos hipoglicemiante, estomático e no tratamento de doenças de pele. Identificou-se no óleo a predominância de ácidos de cadeia longa, como o ursólico. Os ácidos triterpênicos mono-hidroxilados, como o ursólico, apresentam ação anti-inflamatória, antimicrobiana, e antiparasitária. Além disso, apresentam uma baixa ou nenhuma toxicidade, sendo, inclusive, utilizados como aditivos em bebidas, alimentos e em cosméticos (LEUNG; FOSTER, 1996).

Várias propriedades terapêuticas têm sido atribuídas a espécies de Bauhinia, tais como anti-inflamatória, analgésica e antirreumática. Bauhinia forficata, popularmente conhecida como pata de vaca devido às características morfológicas das suas folhas, é utilizada na medicina popular como agente diurético, hipoglicemiante. Poucas são as espécies na família Leguminosae que acumulam óleos essenciais, sendo espécies de Bauhinia uma das exceções. Foram identificados 93,75\% do óleo essencial de B.forficata, correspondendo a 18 substâncias, majoritariamente sesquiterpenos. O principal constituinte foi g-elemeno $(38,42 \%)$, seguido de bulneseno $(17,25 \%)$, epóxi-cariofileno $(9,40 \%)$ e farneseno $(9,11 \%)$. O único constituinte não pertencente à classe dos sesquiterpenos encontrado no óleo essencial de B.forficata foi o hidrocarboneto eicosano, com 0,19\%. Outros óleos de espécies de Bauhinia também apresentaram sesquiterpenos como principais constituintes, indicando uma característica química do gênero Bauhinia (DUARTE-ALMEIDA et al., 2004).

\section{Considerações finais}

Podemos concluir que a abordagem etnofarmacológica tem-se mostrado uma estratégia eficiente na investigação de plantas medicinais para a descoberta de novas entidades terapêuticas. Inserida em um contexto mais abrangente, a etnofarmacologia fortalece a etnobiologia na conceituação da vida, da cultura e das práticas curativas de povos tradicionais. (Albuquerque, 2005). Combinando as informações populares sobre a flora medicinal, adquiridas junto aos sujeitos (comunidades e especialistas tradicionais), com estudos químico/farmacológicos, essa abordagem permite a formulação de hipóteses quanto à atividade farmacológica e à substância ativa responsável pelas ações terapêuticas relatadas, bem como uma triagem no intuito de validação de seu uso.

Estudos relatam que o uso da infusão em botões, flores e folhas preservam os constituintes voláteis, que se degradam pela ação do calor e da água (CASTELLANI, 
1999). Por outro lado, observou-se que o uso relacionado com processo inflamatório, expresso por estados de febre e de vias respiratórias congestionadas, está relacionado com variações climáticas muito frequentes nesta região (SECRETARIA DE ESTADO DA SAÚDE DO PARANÁ, 2013).

O cuidado com a aproximação dos pesquisadores e a relação de identidade foi fundamental para a consolidação dos dados, para isso, um tempo de convivência, o estabelecimento de uma relação de confiança e, posteriormente, a investigação etnobotânica permitiram que os saberes, a cultura e as relações socias ficassem bem estabelecidos.

Por fim, o conhecimento empírico demonstrado pelos sujeitos estudados e descritos neste trabalho abre caminhos para o desenvolvimento de novos estudos sobre essas plantas, visando confirmar cientificamente suas propriedades terapêuticas. Este trabalho permitiu uma interação dialógica entre os saberes oriundos dos participantes e os saberes sistematizados. Os conhecimentos de botânica, biologia, fitoquímica e etnociências puderam ser partilhados e os diálogos entre os estudantes e comunidades foram extendidos e aproximados. Foram avaliadas as técnicas de extração disponíveis. Determinou-se a localização geográfica das espécies escolhidas. Nesta ação, a indissociabilidade ensino-pesquisa e extensão se fizeram presentes nas várias etapas da pesquisa, desde a escolha da espécie, o conhecimento do entorno onde a espécie ocupa seu espaço, as interações ecológicas e os saberes populares da comunidade sobre a planta estudada. A descoberta de óleos essenciais, em quantidades economicamente viáveis e em espécies abundantes na vegetação nativa do litoral, pode constituir uma importante alternativa econômica para os pequenos e médios produtores, além de contribuir para o desenvolvimento sustentável da região.

\section{Referências}

ALBUQUERQUE, U.P. Etnobiologia: Bases Ecológicas e Evolutivas. Recife: NUPEEA, 2013. 166 p.

ALBUQUERQUE, U.P. Introdução à Etnobotânica. Rio de Janeiro: Editora Interciência, 2005. 93p.

AMOROZO, M.C.M. A abordagem Etnobotânica na pesquisa de plantas medicinais. In: Plantas Medicinais: Arte e Ciência. Um guia de estudo interdisciplinar, 1. ed. São Paulo: Editora da Universidade Estadual Paulista, p. 47-68, 1996.

AMOROZO, M.C.M. Uso e diversidade de plantas medicinais em Santo Antonio do Leverger, MT. Acta Botanica Brasilica, v. 16, n. 2, p.189-203, 2002.
ARNOUS, A.H.; SANTOS, A.S.; BEINNER, R.P.C. Plantas medicinais de uso caseiro - conhecimento popular e interesse por cultivo comunitário. Revista Espaço para a Saúde, v. 6, n. 2, p.1-6, 2005.

BATTISTI, C.; GARLET, T.M.B.; ESSI, L.; HORBACH, R.K.; DE ANDRADE, A.; BADKE, M.R. Plantas medicinais utilizadas no município de Palmeira das Missões, RS, Brasil. Revista Brasileira de Biociências, v. 11, n. 3, p.338-348, 2013.

BISHT, A.K.; BHATT, A.; RAWAL, R.S.; DHAR, $\mathrm{U}$. Prioritization and conservation of Himalayan medicinal plants: Angelica glauca Edgew. as a case study. Ethnobotany Research \& Applications, v. 4, p. 11- 23, 2006.

CARVALHO, A.C.B.. Plantas medicinais e fitoterápicos:regulamentação sanitária e proposta de modelo de monografia para espécies vegetais oficializadas no Brasil. Brasília: Universidade de Brasília. Tese (Doutorado em Ciências da Saúde) UnB. p. 1-318, 2011.

COELHO-FERREIRA, M. R. Identificação e valorização das plantas medicinais de uma comunidade pesqueira do litoral paraense (Amazônia brasileira). Belém: Universidade Federal do Pará/Museu Paraense Emílio Goeldi,. Tese (Doutorado em Ciências Biológicas)UFPA/MPEG. p.1-259, 2000.

DUARTE-ALMEID A, J. M., NEGRI, G. e SALATINO, A. Volatile oils in leaves of Bauhinia (Fabaceae Caesalpinioideae). Biochemical Systematics and Ecology, v.32, n.8, p. 747-753, 2004.

GILBERT, B.; FAVORETO, R. Cordia verbenacea DC Boraginaceae. Revista Fitos, v.7, n.1., p.17-25, 2012.

GOMES, E.C.; ELPO, E.R.S.; GABRIEL, M.M.; LOPES, M. Plantas medicinais com características tóxicas usadas pela população do município de Morretes, PR. Revista Visão Acadêmica, v. 2, n. 2, p. 77-80, 2001.

GOTTLIEB, O. R.; MAGALHÃES, M. T. Modified distillation trap. Chemist Analyst, p. 49-114, 1960.

HARVEY, A. Strategies for discovering drugs from previously unexplored natural products. Drug Discovery Today, v. 5, n. 7, p.294-300, 2000.

LEUNG, A.Y.; FOSTER, S. Encyclopedia of common natural ingredients used in food, drug and cosmetics. 2nd ed. New York: John Wiley \& Sons Inc, 1996. 
LORENZI, H. Árvores Brasileiras: manual de identificação e cultivo de plantas arbóreas do Brasil. 2 ed. v. 2. São Paulo: Nova Odessa, 2002. p.384.

LUNARDELLI, C.M.. Plantas medicinais na atenção primária à saúde. Florianópolis: Universidade Federal de Santa Catarina. Dissertação (Mestrado). Centro de Ciências Médicas.p.1-144, 2006.

MATOS, F.J.A, VIANA G.S.B, BANDEIRA, M.A.M. Guia Fitoterápico. 2. ed. revisada. Expressão Gráfica, 2001.

MING, L.C.; AMARAL JUNIOR, A. Ethnobotanical aspects of medicinal plants in the Chico Mendes Extractive Reserve. In: DALY, D.; SILVEIRA, M. (Org.). Floristics and Economic Botany of Acre, Brazil. New York: The New York Botanical Garden, 2003.

MORAES, P.M.; VICOSA, G.N.; YAMAZI, A.K.; ORTOLANI, M.B.T.; NERO, L.A. Foodborne pathogens and microbiological characteristics of raw milk soft cheeseproduced and on retail sale in Brazil. Foodborne Pathogens and Disease, v.6, n.2, p. 245-249, 2009.

PIEKARSKI, P. Análise nutricional e fitoquímica de frutos da Morus alba L. Curitiba: Universidade Federal do Paraná. Dissertação (Mestrado). Setor de Ciências da Saúde. p.1-139, 2013.

RATES, S. M. K. Plants as source of drugs. Toxicon, v. 39, p.603-613, 2001.

RODRIGUES, V.E.G.; CARVALHO, D.A. Plantas medicinais no domínio dos cerrados. Lavras: Editora UFLA, 2001. 180p.

SECRETARIA DE ESTADO DA SAÚDE DO PARANÁ. (2013). Informa Epidemiológico CIEVS Paraná. Disponível em: http://www.saude.pr.gov.br/arquivos/ File/ACS/Informe04.pdf, acessado em 17 de novembro de 2014 .

SILVA, M.S.; ANTONIOLLI, A.G.; BATISTA, J.S.; DA MOTA, C.N. Plantas medicinais usadas nos distúrbios do trato gastrintestinal no povoado Colônia Treze, Lagarto, SE, Brasil. Acta Botanica Brasilica, v. 20, n. 4, p.815-29, 2006.

VIEIRA, R.F., (orgs.). Estratégias para Conservação e Manejo de Recursos Genéticos de Plantas Medicinais e Aromáticas: Resultados da $1^{\circ}$ Reunião Técnica. Brasília (Brasil): Embrapa Recursos Genéticos e Biotecnologia/Instituto Brasileiro do Meio Ambiente e dos Recursos Naturais Renováveis/Conselho Nacional do Desenvolvimento Científico e Tecnológico, 2002. for testing mosquito adulticides for indoor residual spraying and treatment of mosquito nets control of neglected tropical diseases who pesticide evaluation scheme. Geneva: World Heatlth Organization, 2006.

WORLD HEALTH ORGANIZATION. Guidelines 